\title{
Health technology assessment development in China
}

\author{
Yingyao Chen \\ Fudan University \\ David Banta \\ Professor Emeritus, University of Maastricht \\ Zhiliu Tang \\ Fudan University
}

Objectives: This study is to review health technology assessment (HTA) development in China during the past two decades, and to facilitate further development of HTA and its integration into policy making.

Methods: The study depends very much on the extensive experiences of the authors in involvement of HTA in China. In addition, literature review and Web site searching have been used to trace the process of growth of HTA in China.

Results: With its rapid economic development, the Chinese health system has had many achievements in the past 30 years. However, there are some weaknesses that have developed during this period. HTA is traced back to the early 1990s in China. First, HTA knowledge transfer and establishment of HTA units were effective ways to develop HTA in China. By the end of 1990s, the policy makers of the Ministry of Health (MoH) made efforts to merge HTA with policy making to improve the quality and efficiency of health care. The main government authorities related to health technology are the State Food and Drug Administration, the Ministry of Labor and Social Security, and the MoH. Their involvements in HTA are varied.

Conclusion: A technology licensure mechanism based on HTA, including technology permission for use, institution licensure, and workforce licensure, is being gradually carried out by the MoH in China. Moreover, HTA can play an important role in technology market entry, insurance benefit coverage, formulary, clinical pathway, reimbursement, and so on. There is a great opportunity for HTA to be an important part of health reform, especially to help policy makers within the health sector to make difficult decisions.

Keywords: Health technology assessment, Health policy, China

\section{THE HEALTH SYSTEM OF CHINA}

\section{Population and Economics}

China is vast in territory, and China is the most populous country in the world, with 1.3 billion people, of whom 56 percent live in the rural areas in 2006 (4). It is becoming an aging society, with 7.9 percent of total population aged 65 and over. China has been experiencing rapid economic growth for many years, and its gross domestic products (GDP) amounted to 21 trillion Yuan (US\$3 trillion) in 2006, with a GDP per capita of 15973 Yuan (US\$2282) (4). However, the ruralurban differences interact with regional disparities. In China, urban Shanghai ranked 24th in the global human development indicator (HDI) league, just above Greece, while rural Guizhou Province in the southwest of China ranked alongside Botswana (14).

\section{Health Delivery System}

The medical service system in China is based on an urbanrural structure, with wide differences between the two (15). The urban three-tier health service system is composed of the tertiary hospital, the secondary hospital, and the community health center, and the rural three-tier system encompasses 
health institutions at the county, township, and village levels. Most of health facilities are nonprofit. Compared with some developed countries, China does not have a high level of health resources. It had 2.53 hospital or township hospital beds, 1.54 physicians, and 1.1 nurses per 1000 population in 2006 (4).

China has an independent public health system, consisting mainly of two institutions: the Center for Disease Control and Prevention (CDC) and a system of health inspection and supervision (15). The CDC has its own facilities at provincial, city, district, and county levels. The community health centers in the urban area and the township hospital in the rural area bear the responsibility to deliver public health services.

\section{Health System Achievement and Weakness}

Although China's transition from a centrally planned to a market-oriented economy created unprecedented economic growth, reforms in the health sector had both successes and failures. In the past 30 years, the health delivery system has been strengthened dramatically, both in urban and in rural areas, in both infrastructure and in capacity. However, China's healthcare system was criticized for its high costs and low macro-efficiency. Some vulnerable people cannot gain access to essential health care. As professor Hsiao pointed that, "the Chinese healthcare system has twin problems: significant waste and inefficiency as well as a serious shortage of funds (9)."

\section{Health Insurance System}

China has no universal health insurance program. The national Urban Social Medical Insurance Scheme for Employees and Retirees (USMISER) was set up in 1998. Its financing comes from an 8 percent payroll tax, 6 percent from employers and 2 percent from employees, covering essential health care for employees and retirees, and it is operated by the bureau of labor and social security at the city level. There were 180 million insurees by the end of 2007 (6). The New Rural Cooperative Medical Scheme (NRCMS), a governmentrun voluntary insurance program, is to insure rural residents against catastrophic health expenses and to protect them from impoverishment by illness. The central and/or local government at least subsidizes 40 Yuan (US\$5.7) per peasant, with the peasant paying an additional 10 Yuan (US\$1.4) in annual premiums to enroll in the NRCMS plan. By the end of 2007, the NRCMS covered 730 million rural residents (5). To achieve the goal of Essential Health Care for All, the central government has initiated the national Urban Resident Medical Insurance Scheme (URMIS) for people without employment, including children and students in schools, and some provinces have launched pilot projects.

\section{Provider Reimbursement and Its Practice Behavior}

China's health delivery system is dominated by state-owned health facilities, that is, public hospitals. The hospital employs physicians and other health professionals. Although most of hospitals are state-owned, they receive an insufficient appropriation from the government. The hospital's revenues come mainly from user charges and insurance payments, and providers are paid mainly on a fee-for-service basis.

The government's subsidies to the public hospital are very small, amounting to 6 to 7 percent of total revenue in the general hospitals from 1998 to 2005 (8). Such a subsidy policy followed by the macro-economic reform activates the vigor and micro-efficiency of the hospital. Whereas hospitals have become more vigorous, they focus mostly on revenue. The result is a rapid escalation of healthcare expenditures.

In the Chinese health delivery system, most of the physicians work in hospitals, and only a small proportion are private practitioners. Usually, a physician's income is composed of a salary and a bonus from the hospital. A physician's salary is financed in part by the government, but mostly by the hospital. The bonus is linked to seniority, specialty, productivity, and the amount of revenue the physician generates to the hospital. Under such a mechanism, the providers have the tendency to maximize profit: the more services, the more profits. Of course, the providers induce a demand for health care, including high-tech services and new pharmaceuticals, and sometimes these are not necessary. This cost-driving reimbursement mechanism is absolutely dangerous to the construction of the national health insurance scheme from the view of containing healthcare costs.

Recently, separate revenue and expenditure administration is being piloted in some community health centers and township hospitals. This policy tries to cut the relationship or connection of the physician's income and hospitals services or revenues, and the physician will be paid on the performance rather than the revenue. In addition, the health authority is implementing strict budget administration. It will change the provider's behavior from providing more services to focusing on performance, but the long-term impacts will need to be observed.

With the development of USMISER, the medical insurance administrative agency wants to improve the sickness fund's efficiency, and uses other reimbursement methods to pay for the hospital's bill, such as global budgets, average payments for outpatient visits or inpatient admission, but the hospitals always find countermeasures to different reimbursement strategies, such as bargaining with the insurance agencies for the budget, selecting patients, and so on.

\section{Pharmaceuticals}

Pharmaceuticals are a major profit source for healthcare providers in China. The share of pharmaceuticals in Chinese total health expenditures, 50 to 62 percent (18), is much 
higher than in other countries. The percentage of pharmaceuticals in the outpatient expenses and inpatient expenses in China in 2006 were 50.5 percent and 42.7 percent, respectively, reaching the lowest points in recent 10 years (4). There are several reasons why the share of pharmaceutical expense in China tends to be higher than in other industrial countries (2). One explanation for this is that manufacturers recognize that incentives for prescribers strongly favor imported, expensive, brand-name products. Providers are permitted to mark up the price of pharmaceuticals by 15 percent over the wholesale price. In addition to markup, hospitals can bargain with pharmaceutical companies to get a discount as they are the big purchasers. Another incentive, immoral and illegal, is the bonus-under-the-table from the pharmaceutical companies to providers. Because drug expenditures are responsible for the largest share of national health expenditures in China, it is undoubtedly clear that the issue of pharmaceutical cost containment is an especially important issue for the Chinese health sector.

\section{Total Health Expenditure in China}

China's total health expenditures reached 984 million Yuan (US\$141 million) in 2006, making up 4.7 percent of GDP, but only 749 Yuan (US\$107) per capita per year, with 1248 Yuan (US\$178) for urban residents and 362 (US\$52) for rural residents. Healthcare financing came from out of pocket, social health spending, and government spending, with respective shares of 49.3 percent, 32.6 percent, and 18.1 percent (5). A large share of health costs is paid out of pocket. That might result in difficulties of access to health care and negative impacts on health status in the long-run.

The current Chinese government is giving greater priority to social development and building a harmonious society. In October 2007, the Chinese government announced that it will strive to build an essential healthcare system to achieve the goal of "Health for All." Such a commitment shows that health has been identified as a top social priority and that health is considered the basis for human development.

In the past 2 years, there are many discussions concerning how to re-structure a better health system. Eight academic institutions, international agencies, and a consultant company proposed nine options for health system reform to the Chinese central government, and the new health system reform proposal was released for public reviews on October 15,2008 . This, together with growing tax revenue generated by a thriving economy, has led to the introduction of several major reform initiatives. The Chinese government has committed to increasing government funding for health care over the next several years, directed to providing universal basic health care (16). Such a context gives great opportunities for the policy makers, providers, and academies to make use of health resources in an effective, efficient, and equitable way.

\section{HTA DEVELOPMENT IN CHINA}

Obviously, health technology is a very important element of health system. Whatever pharmaceuticals or procedures, whatever equipment or devices, whatever the organization system or the support system, health technology is a dominating determinant of health care, quality of care, and health expenditures. Health technology is always a double-edged sword. It improves the capacity of diagnosis, prevention, and treatment, but is also associated with some negative impacts, such as the side effects of technology, the irrational increase of health expenditure, the ethical and social effects of technology. China is still a developing country, and it is short of health resources, although the populations' expectations are high. Under this basic national condition, health reform should lay stress on how to provide appropriate, costeffective essential health care and health technology to all people. It gives a great opportunity to health technology assessment to address those issues in a clear evidence-based way, especially because the new health reform is at the beginning.

\section{Introduction of HTA to China}

In the 1980s, the World Bank gave strong encouragement to the introduction of HTA to China. In its health loan project, technology assessment was part from the beginning (1). Dr. Banta was invited to conduct some training and research activities at that period. The Ministry of Health (MoH) itself made technology assessment one of the functions of the Department of Science and Education (DSE). In 1991, the MoH sent a delegation to several European countries to study HTA development overseas. In 1992, the MoH sponsored a national conference on scientific research outcome dissemination, and Dr. Jie Chen of Shanghai Medical University, a professor who learned HTA in Europe and the United States, was invited to present on medical technology assessment. The seminar was aimed primarily at staff of some provinces and the $\mathrm{MoH}$ itself. In the same year, another seminar on medical technology assessment was organized by the $\mathrm{MoH}$ in Hangzhou, and Dr. Banta and Dr. Egon Jonsson taught technology assessment. As part of the work in Hangzhou, Dr. Banta and Dr. Jonsson were invited to lecture at a workshop hosted by Prof. Chen at Shanghai Medical University. Those activities were initial efforts to disseminate health technology assessment in China, and international HTA experts acted as an "incubator" to launch its development. There were several underlying motivations for introduction of HTA to China, including studying overseas technology and experiences due to changing policy; looking for some tools to improving safety, effectiveness, and cost-effective issues in health care; and so on.

\section{Early Development (1994-1999)}

Some HTA units were set up by the DSE of MoH for facilitating HTA development in China in the mid-1990s. The 
Table 1. Number of Papers Containing- the Key Words "Technology Assessment" (1998-2007)

\begin{tabular}{lcccccccccc}
\hline & 1998 & 1999 & 2000 & 2001 & 2002 & 2003 & 2004 & 2005 & 2006 & 2007 \\
\hline No. of papers & 91 & 116 & 176 & 231 & 234 & 242 & 295 & 347 & 348 & 421 \\
\hline
\end{tabular}

MoH selected some universities as the sites of HTA units because of their potential capacities. The first HTA Research Center in China, the Medical Technology Assessment \& Research Center, was established at the former Shanghai Medical University (now Fudan University) in January 1994, and Prof Chen Jie was appointed as the Director of this center. Another two HTA units were established in Zhejiang University (Hangzhou) and the former Beijing Medical University, respectively. An evidence-based medicine center was established in the former West China University of Medical Sciences (Chengdu) in 1997. Originally, the different HTA units had different foci, such as economic evaluation of health technology mainly at the Shanghai unit, evaluation of a technology standard for medical equipment at the Hangzhou unit, ethics evaluation at the Beijing unit, and evidence-based medicine at the Chengdu unit. These four centers made up the network for HTA.

In this period, some research with HTA elements was carried out in those HTA units and some universities within the disciplines of social medicine and healthcare management. From its beginning in China, HTA was considered research work, to be carried out mainly by university faculties rather than a professional work. In 1997, the first Chinese HTA report, evaluation of folic acid strategy for prevention of neural tube defects, was submitted to the DSE in the MoH by the HTA center of Shanghai Medical University. Profs Jie Chen and Jianwen Cao and their teams contributed this report.

The Medical Technology Assessment \& Research Center of Fudan University carried out much educational work. It began to offer courses in HTA for undergraduate and graduate students. It organized some workshops for continuing education. In 1996, the book of Medical Technology Assessment, edited by Prof Jie Chen, was published in Shanghai. In 1997, the Center received a 5-year grant from the China Medical Board at New York, focusing on Health Technology Assessment.

\section{Rapid Development (1999 to present)}

In 1999, the International Society of Technology Assessment in Health Care (ISTAHC) selected Shanghai as the site for its winter board meeting. The $\mathrm{MoH}$ took this opportunity to push HTA development. The MoH decided to organize the first National Health Technology Assessment Seminar, while it asked Shanghai Medical University to host the ISTAHC board meeting. It was an important meeting for China's HTA development. Dr. Yu Peng, Vice Minister of $\mathrm{MoH}$, gave a speech at the seminar, and attended a whole-day meeting to listen to the international and domestic experts presenting their HTA work. In her speech, she said that she expected HTA theory and methodology would be applied into the policy-making process. She reviewed the issues in the development of HTA in China, including lack of policies of HTA, insufficient financial supports, lack of understanding of HTA in different groups, and gaps between research of HTA and policy making. She hoped that the $\mathrm{MoH}$ would push HTA development positively in a planned manner, including establishing HTA units and agencies, conducting studies in the context of health reform, facilitating HTA results transferred to policy, carrying out HTA training, and so on (11). This speech demonstrated that senior policy makers realized HTA's value for improving quality and efficiency of health care.

Afterward, the $\mathrm{MoH}$ gradually made efforts to involve HTA into policy making. Meanwhile, there were more HTAs. Based on the Chinese literature database, we searched "technology assessment" and "technology evaluation" as the key words in the health, pharmaceutical, and medicine fields. We found 3,397 papers from the years 1980 to 2008. It appears that the number of papers per year is increasing. The number of papers on HTA in 2007 is approximately four times that of 1999 (Table 1).

The Medical Technology Assessment \& Research Center of Fudan University carried out both research and education. Under China Medical Board support (1997-2003), five workshops were accomplished with hundreds of trainees; ten cases for HTA were drafted for educational use; two books, Clinical Economics and Pharmacoeconomics, were published; sixteen students were involved in training programs for masters and $\mathrm{PhD}$; and some faculty members were sent abroad for visiting scholar programs. HTA was carried out on big-ticket technology, such as technology assessment of gamma knife and magnetic resonance imaging, and some research on reproductive health, such as technology assessment on artificial insemination, in vitro fertilization, and prenatal diagnosis. Most of these studies were supported by the $\mathrm{MoH}$ and other public funds. In 2004, the MoH developed the Key Lab of Health Technology Assessment (KLHTA) at Fudan University, and appointed Prof Jie Chen as the director of the agency. Its mission is to conduct HTA research, education and training, collaboration and exchange, and technical services. In 2007, the WHO designated the KLHTA as a WHO Collaborating Center for Health Technology Assessment and Management, and Prof Chen acted as the director. This HTA agency is not only to facilitate HTA development in China in the context of healthcare reform, but also to participate in the global actions of HTA in the region or in the world. 
Beyond the HTA units, there are some universities, medical associations, and agencies that are involved in HTA in China, but they do not always entitle their works as "HTA." So the real capacity of conducting HTA in China could be stronger than its appearance.

\section{HEALTH TECHNOLOGY MANAGEMENT SYSTEM AND HTA'S INFLUENCES ON HEALTH POLICY}

There are more than twelve ministries or administrations governing the health sector in China. The main actors related to health technology are the State Food and Drug Administration (SFDA), the Ministry of Labor and Social Security (MoLSS) and the MoH (13).

\section{SFDA}

The SFDA is responsible for registration and supervision of pharmaceuticals and medical devices, and especially to the market entry of drugs and medical devices. The SFDA's responsibility and role is mainly based on the Law on Pharmaceutical Administration (enacted on December 1, 2001), the Statute on Pharmaceutical Administration (enacted on September 15, 2002), the Statute on Medical Devices Supervision and Administration (enacted on April 1, 2000), and the Statute on Pharmaceutical for Anesthetic and Mental Health (enacted on November 1, 2005). The law is approved by the China National People's Congress, and the statutes are approved by the State Council.

The Regulation on Pharmaceutical Registration and the Regulation on Pharmaceutical Recall were revised by the SFDA and implemented in the end of 2007. Those two regulations highlight the significance of pharmaceutical safety and re-define the definition of the new pharmaceuticals so as to give priority to innovations in the field of pharmaceuticals. The strengthening of regulations was due to weakness in stewardship of pharmaceuticals in China. The Chinese Finance magazine published a report on registration of pharmaceuticals in 2005, revealing that the State Drug Administration Authority accepted approximately 10 thousand new drug applications, and none of them was really a new molecule. All of them represented only a small change in dosage, route of administration, usage, or packaging (19). Such a process is far from the notion of technology innovation, and it is close to useless for patients. The underlying reason is the drug company wishes to sell a "new" pharmaceutical at a higher price, and the SFDA approved such actions. The common means by which a manufacturer stops producing an old, low-priced drug is to develop, instead, a similar drug with "a little change" and apply for its approval as a new drug. The Chinese idiom called this phenomenon "the same old stuff with a new label" (2). In addition to that, the SFDA did not guard the quality of drugs carefully, and the results were many adverse drug events.
In the Web site of SFDA, we searched the words of "technology assessment" by its own search engine. Unfortunately, not one hit was found. This demonstrates that the decision makers at the SFDA do not have a good understanding of technology assessment, and they do not use technology assessment in their routine management. Fortunately, according to the proposal of health reform issued by October 2008, health economic studies are requested gradually by SFDA when the pharmaceutical company applies for the new drug or patent drug approval.

\section{MoH}

In $\mathrm{MoH}$, there are several departments related to HTA, including departments of Budget and Finance, Personnel, Policy and Regulation, Rural Health, Maternal and Child Health, and Community Health, Hospital Administration, Disease Prevention and Control, and Science and Education.

In the Web site of $\mathrm{MoH}$, we also searched the words "technology assessment" by its own search engine. Fortunately, we had a lot of hits. In the $\mathrm{MoH}$ annual reports by the Minister, technology assessment was always mentioned, and it was regarded as a tool to provide cost-effective health care to people.

The initial facilitator of HTA at the MoH is the DSE. After the first National Health Technology Assessment Seminar in 1999, the DSE of MoH proposed to integrate HTA with technology management, and tried to establish a technology licensure mechanism for emerging technology or high-tech innovations. In September of 2002, a Division of Health Technology Administration was set up within the DSE. Its mission was to be responsible for the technology licensure system in China.

The technology assessment and management of assisted reproductive technology (ART) is a very good case to reflect the integrative mechanism of HTA and technology management in China. In 2000, the DSE contracted with Medical Technology Assessment \& Research Center of Fudan University to do a HTA on ART because there were many issues regarding ART quality and ethical concerns. Dr. Jun Lv and her research team reviewed its ART development in other countries and clinical practices in China, and proposed several policies, mainly focusing on strengthening the stewardship of ART by the government, especially on the ART regulations (10). In 2001, the Regulation on Assisted Reproductive Technology, the Regulation on Sperm Bank, and the related guidelines were issued by the $\mathrm{MoH}$. It demonstrated that the policy makers had realized the importance and value of HTA and were trying to set up the mechanism of HTA for the target technology (17).

This was the first endeavor to implement the technology licensure mechanism in China, which means the government's administrative roles on technology permission, institution licensure, and workforce licensure (12). The technology permission means that the evaluated technology with 
safety and efficacy based on HTA could be used in the healthcare institution by the permission of the health authority. The institution licensure refers to a requirement that institutions should meet minimal requirements set by the government to deliver a certain technology, and those requirements include both hardware and software criteria. The workforce licensure means that the health workforce delivering services of a particular technology should meet some basic requirements, such as educational standards and practical indicators. The top leaders of $\mathrm{MoH}$ have effectively implemented such a mechanism into other technology management areas, and some departments within the MoH have applied such a mechanism into their routine management.

Afterward, prenatal diagnosis was set as one of health policy priorities by the Department of Maternal and Child Health and DSE at the MoH. Medical Technology Assessment \& Research Center at Fudan University conducted the HTA to identify the main barriers to its effective use in 2001. Based on the situation analysis and suggestions for changes, the $\mathrm{MoH}$ formulated the new policy for prenatal diagnosis in China, targeting most of issues the study had found. The Regulation of Prenatal Diagnosis, reflecting and composing the evidence policy, was issued by the MoH in December 2002 (3). So technology assessment was disseminated to the Maternal and Child Health field.

At the MoH, most clinical technology is administrated by the Department of Hospital Administration (DHA). DHA has many activities to implement a technology licensure mechanism. Such efforts were applied on technology administrative on man-made implants of hip joint, knee joint, and other joints: interventional technology for nervous system diseases, cardiovascular diseases, and others; organ transplantations; and so on.

For the future development of HTA with health policy, different departments within the MoH have different plans. A few years ago, DSE proposed a regulation on health technology licensure, but this has not yet been approved. DSE classifies health technology, not just medical technology, as having five categories, including emerging technology, approved technology with some constraints, approved technology with wide dissemination, lagging technology, and forbidden technology. It proposes to establish a national HTA committee and HTA expert's database, to assess technology by the HTA unit, and to implement the accreditation system for the HTA unit and HTA staffs. This proposal draws some experiences from European countries, Australia, and Canada. The DHA drafted a regulation on clinical application of medical technology, and released it to the public for review last year. It is still under discussion. The regulation states that clinical application of medical technology should be consistent with the principles of science, safety, effectiveness, cost-effective, and ethical acceptance. It classifies medical technology into three categories. The first category of medical technology is technology with confirmed safety and effectiveness; the second category of medical technology is technology with confirmed safety and effectiveness, but with some ethical concerns and some risks; and the third category of medical technology is technology with pending safety and effectiveness or technology with strong ethical issues and high risks. It requires that the second and third categories of technology should be evaluated by the third party before they are used in practice, especially the third-category technologies should pass the review process organized by the $\mathrm{MoH}$, and the review includes evaluation of safety, effectiveness, and social impacts. The third party should be an independent institution with effective organization and administration systems, hold the top position in medical fields, and have a reputation of scientific, serious, and academic performance.

\section{MoLSS}

MoLSS is responsible for the financing and operating of USMISER and URMIS, but it is not responsible for NRCMS, which is governed by the MoH. The MoLSS has many reimbursement policies, such as for the lists of drugs, procedures, and facilities covered by the basic health insurance and their payments. The MoLSS has three positive lists reimbursed by the USMISER, including pharmaceuticals, services of diagnosis and treatment, and facility standards for health care. It implements the designated administrative system, and those designated hospitals and pharmacies are administrated by the local labor and social security authorities.

In its Web site, we searched the words "technology assessment" by its own search engine. Unfortunately, few hits related to HTA were found. We reviewed some reports presented by the Minister and the Vice Ministers, and we found that the MoLSS is putting much effort into the expansion of health insurance schemes. At the national medical insurance conference this year, there are five main tasks for the authority: four tasks belonging to expanding health insurance coverage, and only one for improving medical insurance administration, including studying how to modify benefit packages, improve reimbursement methods, and establish quality control criteria. Similarly, in the 5-year Strategic Planning for Labor and Social Security Development (2006-10), it describes objectives of health insurance, but does not mention technology assessment.

The national formulary for basic health insurance and injury insurance was issued in 2004, and it was modified based on the 2000 version. It was composed of 823 Traditional Chinese Medicine (TCM) drugs and 1031 Western drugs in 2004. Each province can modify the national formulary according to local conditions. In addition, there are some drugs to be added or deleted every year. The vice minister of the MoLSS stated that there are four principles met in the national formulary. The first is to ensure reasonable pharmaceuticals provision for insurees and to control irrational pharmaceutical expenses. Second is to be consistent with scientific developments in clinical medicine. Third is to ensure that basic health demands are met, taking economic 
status into consideration. Fourth is to implement an expert reviews system and to ensure that the process is open, fair, and equitable. In the process of modifying this version of the national formulary, around 3000 professionals were involved and gave their opinions. In the approval section, 1648 experts reviewed the formulary. When we looked at the process of approval, we believed that the evaluation mechanism existed, but we could not identify whether they were based on "evidence" rather than "experience."

Beyond that, pharmacoeconomic studies or pharmaceutical outcome research studies have been increasingly conducted in China recently. Some study results have been submitted to the policy makers at the MoLSS, and that evidence has some impact on policy making.

Although the tripartite administrative system has its rationality, it also leads to many gaps that are due to contradictions and omissions among stake holders. Sometimes, technology is administrated by multiple parties by different policies; sometimes technology is out of control. Such a system is likely to produce inconsistent polices.

Regarding HTA influences on the policy maker, we witness some positive cases in which policy makers have made use of HTA and evidence-based information. The policy makers at the $\mathrm{MoH}$ have started to use the word of technology assessment quite often, and they have contracted with HTA units to conduct some activities. However, the formal contract system is still being developed, and the academic institutes are living more on the research grants than the contracts with the government agencies. It seems that dissemination and promotion of HTA theory and methods have not influenced some policy makers. There are still some challenges ahead.

\section{DISCUSSION}

With positive economic development, China is developing a good healthcare system that incorporates modern health technology. China has been almost entirely self-sufficient in drugs, but international pharmaceutical companies also enter the Chinese market with their innovative drugs or genetic drugs with brand names. China has been making efforts to develop the medical equipment or device industry, but most high-tech products used in hospitals is still imported. With the modernization of health technology, technology assessment has entered the vision of all stakeholders. Moreover, stakeholders are attaching importance to costs and benefits of health technology, leading to opportunities for HTA. Furthermore, China is re-structuring its health system, and mainly changing some irrational incentive mechanisms, and HTA has an important role on achieving this.

\section{(i) HTA Has Been Adopted by the Policy Makers to Some Extent}

When we review the history of HTA in China, we find that HTA has been a policy language by some policy makers. Although some policy makers do not know the term "tech- nology assessment", they have knowledge of risks, benefits, costs, and social implications of specific health technologies. We are happy to see some policy makers integrate HTA with policy and try to embed it into the Chinese context. There is some evidence to demonstrate that the $\mathrm{MoH}$ has integrated HTA into policy making mechanism, and such efforts have some positive impacts.

\section{(ii) HTA Still Needs to Be Promoted, and to Be Widely Adopted}

Compared with the international HTA community, HTA in China is still in the development stage. HTA is not widely applied. There is not much evidence that HTA is used extensively in health resource allocation decisions, definition of the public health package paid by government, technology entry and withdrawal, and other such technological policies. Policy makers might have some awareness of HTA, but they do not use HTA in routine decisions. In particular, it is necessary to disseminate HTA theory and methods to policy makers in the macro health sector, such as the authorities for drugs and social security.

\section{(iii) The Health Technology Assessment Framework Needs to Be Coordinated}

In China, HTA is scattered among many administrative areas. There is no national HTA commission to coordinate HTA at the different authorities, to identify the national priority of HTA, or to ensure the consistency among policies issued by different authorities. It is necessary to restructure the HTA framework and clarify the HTA role for the policy maker regarding health reform, or to establish a national HTA commission across authorities to coordinate HTA work.

In addition, the mission of different authorities should be adjusted or confirmed. SFDA is responsible for the market entry for all health technology, including pharmaceuticals, equipment and devices, and it focuses on safety and efficacy. The $\mathrm{MoH}$ is responsible for the supervision of health technology used in the healthcare institutions, including monitoring of health technology in the postmarket stage, implementing technology permission and licensure for institutions and professionals, and insuring safety and efficacy evaluation for medical procedures. MoLSS is responsible for the benefit package covered by the health insurance scheme, and it focuses on effectiveness and cost-effectiveness.

\section{(iv) Health Technology Assessment Should Be Conducted for Different Kinds of Technology}

In China, the government should encourage all stake holders to conduct HTA, and provide the HTA reports to the government and public. The HTA units, academics, industries, and healthcare institutions can work on this. The process of conducting HTA should follow the guidelines with enough transparency so that HTA can be monitored (7). The 
government should subsidize most HTA activities with public funds so that HTA is free from conflicts of interest.

\section{CONTACT INFORMATION}

Yingyao Chen, PhD (yychen@ shmu.edu.cn) Professor, The Key Lab of Health Technology Assessment, The WHO Collaborating Center for Health Technology Assessment and Management, Fudan University, 138, Yi Xue Yuan Road, Shanghai, 200032, China

David Banta, MD, MPH (HD.Banta@ orange.fr), 9 route de Bragelogne, 10210 Villiers-de-Bois, France

Zhiliu Tang, M.D (zltang@shmu.edu.cn), Lecturer, The Key Lab of Health Technology Assessment, The WHO Collaborating Center for Health Technology Assessment and Management, Fudan University, 138, Yi Xue Yuan Road, Shanghai, 200032, China

\section{REFERENCES}

1. Banta D, Luce B. Health technology assessment and its assessment. Oxford: Oxford University Press; 1993.

2. Chen Y, Schweitzer SO. Issues in drug pricing, reimbursement, and access in China with references to other Asia-Pacific region. Value Health. 2008;11:S124-S129.

3. Chen Y, Qian X, Tang Z, et al. Situation analysis of prenatal diagnosis technology utilization in China: Current situation, main issues and policy implications. Int J Technol Assess Health Care. 2004;20:524-530.

4. China Ministry of Health. China health statistics yearbook 2007. Beijing: China Union Medical University Press; 2007

5. China Ministry of Health. China health statistics digest 2008. Beijing: the Peking Union Medical College Press. http:// www.moh.gov.cn/publicfiles/business/htmlfiles/zwgkzt/ptjty/ 200805/35671.htm. (accessed September 20, 2008).
6. China Ministry of Labor and Social Security. Situation of social insurance in China. http://www.molss.gov.cn/gb/news/200711/29/content_212193.htm. (accessed September 20, 2008).

7. Drummond MF, Schwartz JS, Jonsson B, et al. Key principles for the improved conduct of health technology assessment for resource allocation decisions. Int J Technol Assess Health Care. 2008;24:244-258.

8. E Q, Li C, Han P, Tian D, Chen Y. In-depth analysis on public hospital deviating their social responsibilities. Chin Health Resour. 2007; 10:278-280.

9. Hsiao W. The Chinese health care system: Lessons for other nations. Soc Sci Med. 1995;41:1047-1055.

10. Lv J, Tang Z, Dong H, et al. Study on management of assisted reproductive technology in China. Chin J Hosp Admin. 2002; 18:581-583.

11. Peng Y. Medical technology assessment. Chin Health Resour. 1999;2:3-4.

12. Qi G. Health technology assessment and health technology admission management. China Evid Based Med. 2001;1:6566.

13. Tang Z, Chen Y. Some ideas on health technology management in China. Chin Health Resour. 2007;10:178-179.

14. United Nation Development Program. Human development report 2005. UNDP. 2005.

15. United Nations Health Partners Group in China. A health situation assessment of the People's Republic of China. Beijing; July 2005.

16. Yip W, Hsiao WC. The Chinese health system at a crossroads. Health Aff (Millwood). 2008;27:460-468.

17. Yu X. Exploration of health technology assessment and evidence-based permission. China Evid Based Med. 2004;4:1014.

18. Zhang R, Hu S. An analysis of China's drug expense growth. Chin J Hosp Admin. 2002;18:648-650.

19. Zhang YG, Dai W. The puzzle of the pharmaceutical price. Finance. 2005;149. http://caijing.hexun.com/text.aspx? $1 \mathrm{~m}=2553 \& \mathrm{id}=1464234$. (accessed September 20, 2008). 